Poster Section

\title{
Additional resource for diabetes diagnostics in animals and humans
}

\author{
Vladimir Vitalyevich Drozdov \\ The Russian Homeopathic Society, Russia
}

\begin{abstract}
Veterinary doctors often observe cases of unexplained elevated glucose and ketones in urine of domestic animals without any other signs of diabetes. We studies these effects from the standpoint of the phenomenon of interdependent conditions in animals and humans, described by T.V.Novosadyuk in 2000. She was the first to provide a theoretical and practical foundation for clinical cases of simultaneously developing similar diseases in domestic animals and their owners.
\end{abstract}

During the last 5 years we studied health of humans in families where domestic animals are affected by the laboratory abnormalities described above. In vast majority of cases it has been found out that animal owners have diabetes mellitus of variable severity.

At the same time there were no disorders of carbohydrate metabolism in animal owners in 11 cases. We recommended members of these families to undergo a specialized examination. In all of these cases latent diabetes mellitus was found in humans who had especially close relationships with animals. These findings led to initiation of treatment in humans.

At the same time animals were treated with a collar with a linen sack attached containing Peganum Harmala 30 globules. Repeated laboratory tests were performed after one month of such treatment. Normalization of laboratory variables was observed in all of the cases.

Based on the study results we developed an algorhythm of activities that helps to diagnose early and latent forms of diabetes mellitus in domestic animals and their owners. This algorhythm includes:

- test for glucose and/or ketones in animal urine after correction of feeding and care defects.

- blood and urine glucose tests in family members of animal owners. In cases of deviations from normal values we recommended them to consult appropriate specialists and begin treatment immediately.

- animals are given collars with Peganum Harmala 30 globules in a linen sack attached.

- granules are removed when laboratory values normalize in animals. Control urinalysis is performed every three months durign a year.

This approach is especially useful in latent early forms of diabetes mellitus when abnormal findings in animals or their owners enable us to suspect a similar disease in another.

In such a way, the suggested algorithm is effective for organization of preclinical diagnostics in both domestic animals and their owners. In the future it is possible to enrich not only veterinary but also medical practice 
with new options for effective patient aid by practical development of the use of animal and human interdependent conditions.

Keywords: diabetes mellitus, domestic animals, Peganum Harmala, interdependent conditions in animals and their owners.

\section{(c)) EY-NC-ND Licensed to GIRI}

Support: authors declare that this study received no funding

Conflict of interest: authors declare there is no conflict of interest

Received: 01 June 2012; Revised: 10 August 2012; Published: 30 September 2012.

Correspondence author: Vladimir Vitalyevich Drozdov, vladimir-drozdov@yandex.ru

How to cite this article: Drozdov VV. Additional resource for diabetes diagnostics in animals and humans. Int J High Dilution Res [online]. 2012 [cited YYYY Month dd]; 11(40):200-201. Proceedings of the XXVI GIRI Symposium; 2012 Sep 20-22; Florence (Italy). GIRI; 2012; Available from: http://www.feg.unesp.br/ ojs/index.php/ijhdr/article/view/561/607 